\title{
The TLR9-MyD88 pathway is critical for adaptive immune responses to adeno- associated virus gene therapy vectors in mice
}

\author{
Jiangao Zhu, Xiaopei Huang, and Yiping Yang \\ Departments of Medicine and Immunology, Duke University Medical Center, Durham, North Carolina, USA.
}

\begin{abstract}
Recombinant adeno-associated viruses (AAVs) have been used widely for in vivo gene therapy. However, adaptive immune responses to AAV have posed a significant hurdle in clinical application of AAV vectors. Recent advances have suggested a crucial role for innate immunity in shaping adaptive immune responses. How AAV activates innate immunity, and thereby promotes AAV-targeted adaptive immune responses, remains unknown. Here we show that AAV activates mouse plasmacytoid DCs (pDCs) via TLR9 to produce type I IFNs. In vivo, the TLR9-MyD88 pathway was crucial to the activation of $\mathrm{CD8}^{+} \mathrm{T}$ cell responses to both the transgene product and the AAV capsid, leading to loss of transgene expression and the generation of transgene productspecific and AAV-neutralizing antibodies. We further demonstrate that TLR9-dependent activation of adaptive immunity targeting AAV was mediated by type I IFNs and that human pDCs could be activated in vitro to induce type I IFN production via TLR9. These results reveal an essential role for the TLR9-MyD88-type I IFN pathway in induction of adaptive immune responses to AAV and suggest that strategies that interfere with this pathway may improve the outcome of AAV-mediated gene therapy in humans.
\end{abstract}

\section{Introduction}

The adeno-associated virus (AAV) is a non-enveloped, singlestranded DNA virus with a genome of approximately $5 \mathrm{~kb}$. It is a member of the Parvoviridae family and requires a helper virus such as an adenovirus or herpes simplex virus for replication. Despite a limited packaging capacity (less than $4.7 \mathrm{~kb}$ ), the AAV has many attractive features for use as a vector for in vivo gene therapy, including the ability to transduce a variety of cells, low immunogenicity and toxicity, and the ability to establish long-term expression of the transgene in vivo (1). So far, AAV vectors have been used in preclinical and clinical studies for a variety of diseases, including hemophilia (2-5), Duchenne muscular dystrophy $(6,7)$, $\alpha 1$-antitrypsin deficiency $(8,9)$, and cystic fibrosis $(10,11)$. Among 9 serotypes of AAV that have been developed for gene therapy, serotype 2 (AAV2) is the most extensively studied (1).

The ability of AAV vectors to achieve long-term expression of the transgene product has been attributed to their relatively low immunogenicity (12-14). However, in some experimental settings, attendant immune responses have compromised the outcome of $A A V$-mediated gene therapy. In fact, for this reason, AAV vectors have been developed as a vaccine vehicle for infectious diseases and cancer (15-17). Several factors may influence the occurrence of immune responses to $\mathrm{AAV}$, including the vector dose and serotype, the nature of the transgene, the route of administration, a preexisting immunity to AAV, and the host species (18). It has been suggested that activation of a transgene-specific $\mathrm{T}$ cell response is due to cross-presentation of phagocytosed transgene-derived

Conflict of interest: The authors have declared that no conflict of interest exists. Nonstandard abbreviations used: AAV, adeno-associated virus; AAV2-GFP, AAV2 encoding GFP; AAV2-HA, AAV2 encoding HA; AAV2-lacZ, AAV2 encoding lacZ; Ad-lacZ, E1-deleted adenovirus encoding lacZ; cDC, conventional DC; hIFN- $\alpha$, human IFN- $\alpha$; ODN, oligodeoxynucleotide; pDC, plasmacytoid DC; vg, viral genomes. Citation for this article: J. Clin. Invest. 119:2388-2398 (2009). doi:10.1172/JCI37607. antigens in the context of MHC class I by DCs $(15,19)$. In addition, cross-presentation of the input vector capsid proteins by DCs can activate a capsid-specific $T$ cell response (20-23). Furthermore, efficient activation of a B cell response by AAV vectors leads to production of neutralizing antibodies against viral capsids, which limit effective re-administration of the vector (24-26). Collectively, these observations suggest that AAV vectors are not intrinsically inert in eliciting host immune responses.

The concern for immune responses to AAV vectors has been substantiated by the outcome of a recent clinical trial in hemophilia B patients (5). In that trial, hepatic delivery of AAV2 vectors encoding factor IX led to therapeutic levels of transgene-encoded factor IX in one patient. However, the therapeutic levels of factor IX were only transient. The gradual decline in factor IX was accompanied by a transient transaminitis and the detection of AAV capsid-specific T cells. Overall, the patient's clinical course was compatible with immune-mediated destruction of AAVtransduced hepatocytes. Taken together, the above observations in mice and humans suggest that adaptive immune responses to $A A V$ vectors have posed a major challenge in AAV-mediated gene therapy in vivo.

Critical for the development of effective strategies to circumvent these hurdles is understanding what controls the induction of adaptive immunity to AAV. Recent advances in immunology have suggested a crucial role for the innate immune system in promoting adaptive immune responses $(27,28)$. The phylogenetically conserved innate immune system represents the first line of defense against invading pathogens through recognition of pathogenassociated molecular patterns (PAMPs) by a set of pattern recognition receptors (PRRs) (29). The best-studied family of PRRs is the TLRs, which are expressed on various innate immune cells such as DCs and macrophages. Upon recognition of PAMPs, TLRs trigger a series of signaling cascades leading to induction of antimicrobial genes and inflammatory cytokines, which results in direct killing 

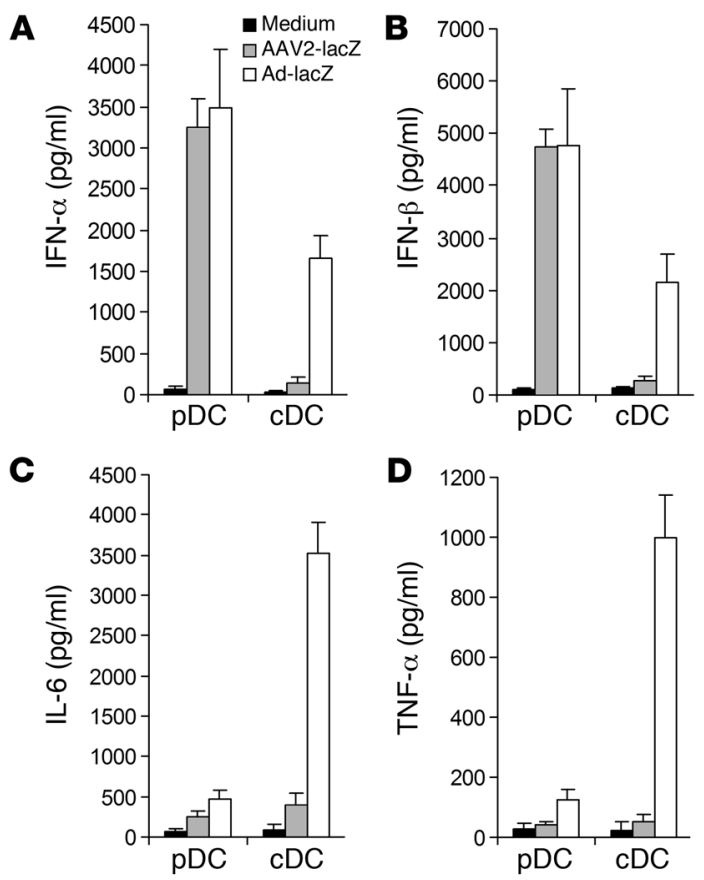

of the invading pathogens as well as promotion of the initiation of adaptive immune responses (27).

How AAV activates the innate immune system remains unknown. In this study, utilizing DCs deficient for genes involved in the TLR pathways, we showed that AAV2 activated plasmacytoid DCs ( $\mathrm{pDCs}$ ) to produce type I IFNs. The innate immune recognition of AAV by pDCs was mediated by TLR9 and dependent on MyD88. Activation of the TLR9-MyD88 pathway was independent of the nature of the transgene. Similarly, other serotypes of AAV, such as AAV1 and AAV9, also activated innate immunity through the TLR9-MyD88 pathway. In vivo, the TLR9-MyD88 pathway was critical for the activation of $\mathrm{CD}^{+} \mathrm{T}$ cell responses to both the transgene product and the AAV capsid, leading to the loss of transgene expression, and the formation of anti-transgene antibody and neutralizing antibodies to AAV vectors. This was mediated by TLR9-induced production of type I IFNs. We further demonstrated that AAV vectors also activated human pDCs to induce type I IFNs via TLR9. Collectively, these observations suggest that strategies to block the TLR9-MyD88-type I IFN pathway may improve the clinical outcome of AAV-mediated gene therapy.

\section{Results}

$A A V 2$ activates $p D C$ s to produce type I IFNs. Studies have shown that both pDCs and conventional DCs (cDCs) play a pivotal role in innate immune sensing of viruses (30). Indeed, we have demonstrated that the innate immune recognition of adenoviral vectors

\section{Figure 2}

AAV2 activates endogenous pDCs, but not non-pDCs, to produce type I IFNs. Splenic pDCs, cDCs, hepatic Kupffer cells (KC), or peritoneal macrophages $(\mathrm{M} \Phi)\left(2.5 \times 10^{5}\right.$ each) were either unstimulated or stimulated with AAV2-lacZ $\left(5 \times 10^{9} \mathrm{vg}\right)$ or Ad-lacZ (MOI of 250 ) for 18 hours. The cultured supernatants were assayed for the secretion of IFN- $\alpha$ (A) and IL-6 (B). Representative data of 3 independent experiments are shown.

\section{Figure 1}

AAV2 mainly stimulates bone marrow-derived pDCs to secrete type I IFNs. pDCs and cDCs were generated from bone marrow cells in the presence of Flt-3 ligand and GM-CSF, respectively, and purified by FACS sorting. Cells $\left(1 \times 10^{6}\right)$ were then stimulated with AAV2-lacZ $\left(2 \times 10^{10} \mathrm{vg}\right.$ ) or Ad-lacZ (MOI of 250) or left unstimulated (medium) for 18 hours, and the supernatants were assayed for the secretion of IFN- $\alpha$ (A), IFN- $\beta$ (B), IL-6 (C), and TNF- $\alpha$ (D) by ELISA. Representative data of 3 independent experiments are shown.

by pDCs is mediated by TLR9, whereas that by non-pDCs such as CDCs and macrophages is TLR independent (31). We thus utilized both pDCs and cDCs to study innate immune response to AAV. pDCs and cDCs were generated from bone marrow cells in the presence of Flt-3 ligand and GM-CSF, respectively, as we previously described (31). pDCs and cDCs, identified as $\mathrm{CD} 11 \mathrm{c}^{+} \mathrm{B} 220^{+} \mathrm{mPDCA}-1^{+}$and $\mathrm{CD} 11 \mathrm{c}^{+} \mathrm{B} 220^{-} \mathrm{mPDCA}-1^{-}$, respectively, were then purified by FACS sorting and stimulated with recombinant AAV2 encoding lacZ (AAV2-lacZ; $2 \times 10^{10}$ viral genomes [vg]) or E1-deleted adenovirus encoding lacZ (Ad-lacZ; MOI of 250) for 18 hours, and the cultured supernatants were assayed for the secretion of type I IFNs such as IFN- $\alpha$ and IFN- $\beta$ and proinflammatory cytokines such as IL- 6 and TNF- $\alpha$. Similar to those infected with Ad-lacZ, pDCs stimulated with AAV2-lacZ produced high levels of IFN- $\alpha$ (Figure 1A) and IFN- $\beta$ (Figure 1B) but very low levels of IL-6 (Figure 1C) and TNF- $\alpha$ (Figure 1D). However, little or no type I IFNs or proinflammatory cytokines were produced by cDCs upon AAV2-lacZ infection (Figure 1). This was in striking contrast to $\mathrm{cDCs}$ stimulated with Ad-lacZ, which produced high levels of IL-6 (Figure 1C) and TNF- $\alpha$ (Figure 1D) as well as IFN- $\alpha$ (Figure 1A) and IFN- $\beta$ (Figure 1B). The dose and the time point chosen for AAV2-lacZ in these studies were based on results from our pilot experiments, in which optimal responses were obtained with DCs stimulated for 18 hours at $2 \times 10^{10} \mathrm{vg}$ (Supplemental Figure 1; supplemental material available online with this article; doi:10.1172/JCI37607DS1), and the dosing for Ad-lacZ was based on our published data (31). Collectively, these results indicate that AAV2-lacZ mainly activates pDCs to produce type I IFNs.

A

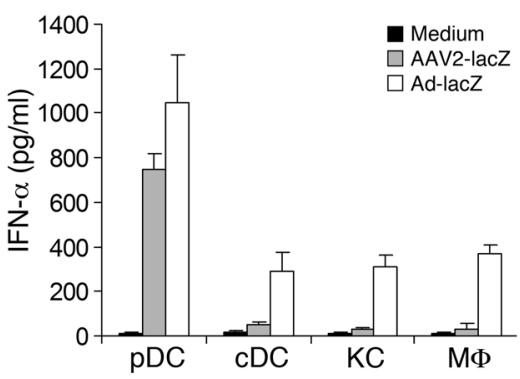

B

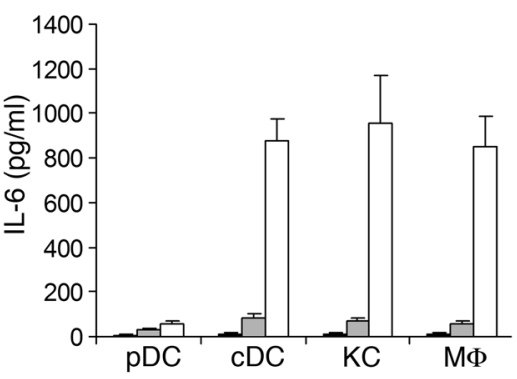



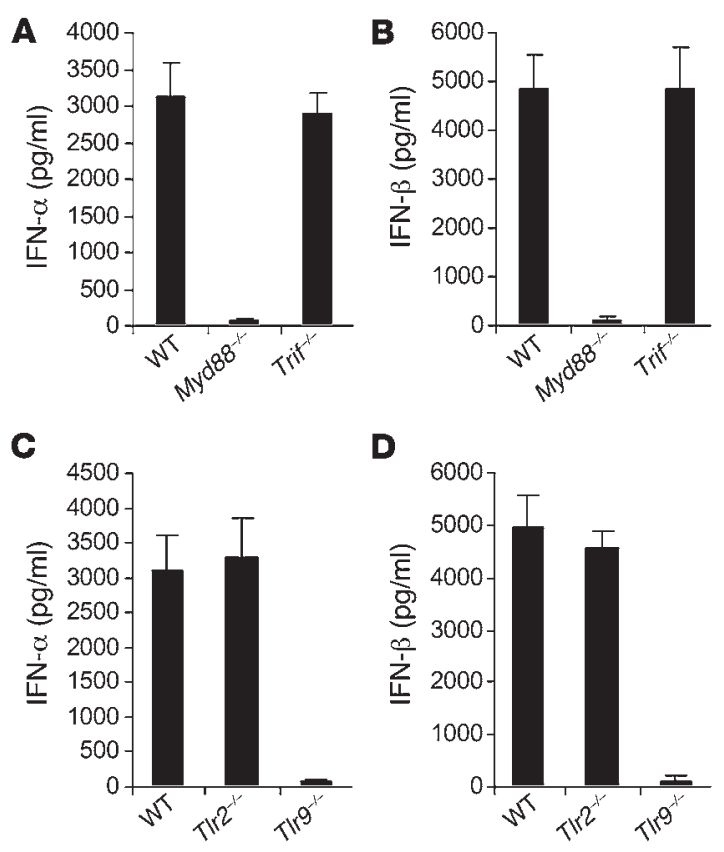

We next examined whether endogenous $\mathrm{pDCs}$ and $\mathrm{cDC}$ behave similarly in response to AAV2-lacZ infection. Splenic pDCs and cDCs were purified by FACS sorting, and the purified DCs were stimulated with AAV2-lacZ or Ad-lacZ and measured for secretion of IFN- $\alpha$ and IL-6. Again, similar to Ad-lacZ, AAV2-lacZ stimulated endogenous pDCs, but not cDCs, to secrete IFN- $\alpha$ (Figure 2A). In contrast to adenoviral infection, no significant levels of IL- 6 were produced by endogenous $\mathrm{CDCs}$ upon AAV infection (Figure $2 \mathrm{~B}$ ). We also investigated how other non-pDCs such as macrophages and hepatic Kupffer cells responded to AAV infection, as the liver is one of the major targets in AAV-mediated gene therapy (5). Purified peritoneal macrophages and hepatic Kupffer cells were stimulated with AAV2-lacZ or Ad-lacZ and assayed for the secretion of IFN- $\alpha$ and IL-6. Our data indicated that freshly isolated Kupffer cells and macrophages could not produce significant levels of IFN- $\alpha$ or IL- 6 upon AAV infection, in contrast to the infection with adenovirus (Figure 2). These results further confirm that AAV mainly activates $\mathrm{pDC}$, but not non-pDCs, to produce type I IFNs.

Innate immune recognition of $A A V 2$ is mediated by TLR9 and dependent on $M y D 88$. We next investigated whether TLRs were involved in the induction of type I IFNs by pDCs upon AAV infection. Since all TLR signaling is mediated by MyD88 and/or TRIF (29), pDCs deficient for MyD88 (Myd88 ${ }^{-/-}$) or TRIF (Trif $\left.{ }^{\prime-}\right)$ were tested for their ability to produce type I IFNs upon AAV infection. pDCs generated from bone marrow cells of Myd88-/- or Trif /- C57BL/6 mice were stimulated with AAV2-lacZ and assayed for type I IFN secretion. The production of both IFN- $\alpha$ (Figure 3A) and IFN- $\beta$ (Figure 3B) by $M y d 88^{-/-}$pDCs was abolished, whereas that by Trif $/-$pDCs was not affected compared with the WT pDCs (Figure 3). These data indicate that the production of type I IFNs by pDCs in response to AAV2 was TLR mediated and dependent on MyD88.

Which TLR then mediated the MyD88-dependent production of type I IFNs by pDCs upon AAV infection? Among all TLRs characterized to date, only TLR7, TLR8, and TLR9 are known to mediate MyD88-dependent production of type I IFNs (29). Since the known ligands for TLR7 and TLR8 are single-stranded RNA,

\section{Figure 3}

PDC recognition of AAV2 is mediated by TLR9 and dependent on MyD88. (A and B) pDCs $\left(1 \times 10^{6}\right)$ generated from bone marrow cells of WT, Myd88-/-, or Trif ${ }^{--}$C57BL/6 mice were purified and stimulated with AAV2-lacZ $\left(2 \times 10^{10} \mathrm{vg}\right)$ for 18 hours, and the supernatants were assayed for the secretion of IFN- $\alpha(\mathbf{A})$ and IFN- $\beta$ (B) by ELISA. (C and D) pDCs generated from bone marrow cells of WT, $\mathrm{TIr2}^{-/-}$, or TIr9-/- C57BL/6 mice were stimulated with AAV2-lacZ for 18 hours, and the supernatants were assayed for the secretion of IFN- $\alpha$ (C) and IFN- $\beta$ (D) by ELISA. Representative data of 3 independent experiments are shown.

and AAV is a single-stranded DNA virus, we hypothesized that a likely candidate to mediate induction of type I IFNs by pDCs was TLR9. To test this, we examined whether pDCs generated from Tlr9-/- C57BL/6 mice secreted type I IFNs upon AAV infection.

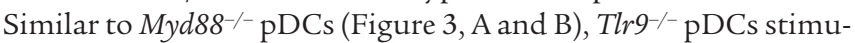
lated with AAV2-lacZ failed to secrete IFN- $\alpha$ (Figure $3 \mathrm{C}$ ) or IFN- $\beta$ (Figure 3D), whereas production of these type I IFNs was not affected in $T l r 2^{-/-}$or WT pDCs upon AAV infection. We further showed that the up-regulation of CD86 was abolished in $\operatorname{Tlr}^{-/-}$ pDCs compared to the WT control (Supplemental Figure 2), suggesting $\mathrm{PDC}$ maturation upon AAV2 infection is also dependent on TLR9 signaling. Taken together, these observations indicate that $\mathrm{pDC}$ maturation and production of type I IFNs upon AAV infection is mediated by the TLR9-MyD88 pathway. Similar results were obtained with pDCs generated from WT, $M y d 88^{-/-}$, or $\operatorname{Tl} 9^{-/-}$BALB/C mice (data not shown).

The TLR9-dependent sensing of AAV also suggests that the ligand for TLR9 recognition is viral DNA. Since the AAV stock was produced by transfecting 293 cells with the vector and the helper plasmids, followed by purification with heparin affinity chromatography as described (32), there was a concern about potential contamination of the purified AAV with residual plasmid DNA, which may account for the observed TLR9-dependent activation of pDCs. To rule out this possibility, AAV2-lacZ was treated again with DNase I and used for stimulating pDCs. Our data showed that $\mathrm{pDCs}$ stimulated with DNase I-treated AAV produced levels of IFN- $\alpha$ (Figure $4 \mathrm{~A}$ ) and IFN- $\beta$ (Figure 4B) similar to those stimulated with untreated AAV, suggesting that viral DNA, but not the
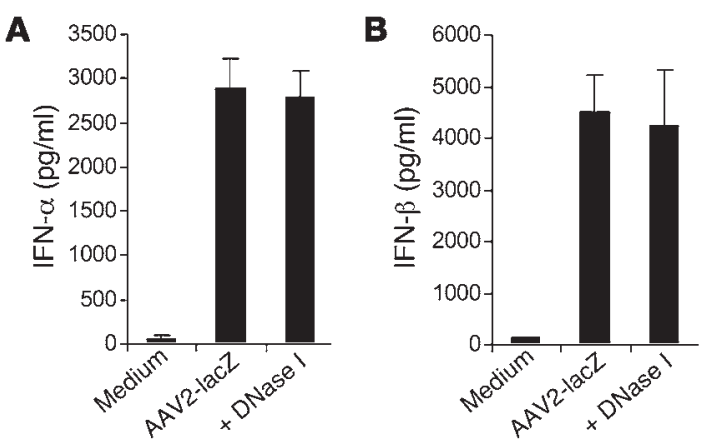

\section{Figure 4}

DNase I treatment does not affect the ability of AAV to stimulate pDCs. pDCs $\left(1 \times 10^{6}\right)$ generated from bone marrow cells were purified and stimulated with AAV2-lacZ $\left(2 \times 10^{10} \mathrm{vg}\right)$ or DNase l-treated (30 minutes at $37^{\circ} \mathrm{C}$ ) AAV2-lacZ for 18 hours, and the supernatants were assayed for the secretion of IFN- $\alpha(\mathbf{A})$ and IFN- $\beta$ (B) by ELISA. Representative data of 2 independent experiments are shown. 

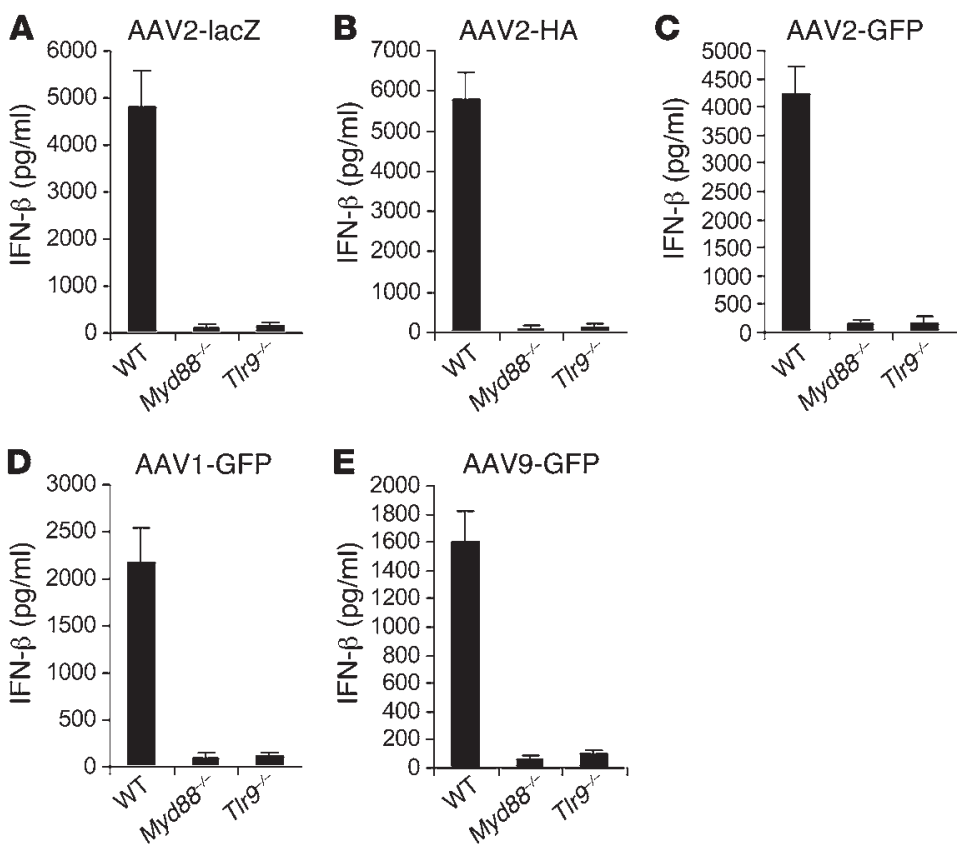

contaminating plasmid DNA, is responsible for the stimulation of TLR9 in pDCs.

Activation of the TLR9-MyD88 pathway by AAV is independent of the nature of the transgene or $A A V$ serotypes. We next sought to determine whether the innate immune recognition of AAV2 encoding other transgenes was also dependent on the TLR9-MyD88 pathway. To

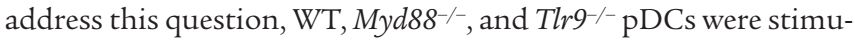
lated with AAV2-lacZ, AAV2 encoding influenza hemagglutinin (AAV2-HA), or AAV2 encoding GFP (AAV2-GFP) and examined for the secretion of IFN- $\beta$. Similar to AAV2-lacZ (Figure 5A), neither AAV2-HA (Figure 5B) nor AAV2-GFP (Figure 5C) stimulated Tlr $9^{-/-}$or $M y d 88^{-/-}$pDCs to produce IFN- $\beta$, suggesting that the activation of the TLR9-MyD88 pathway by AAV is independent of the nature of the transgene that AAV encodes.

Although AAV2 is the most extensively studied AAV vectors, other serotypes of AAV have also been developed as vectors for gene therapy (1). We thus examined whether the innate immune recognition of other AAV serotypes was also mediated by the TLR9MyD88 pathway. WT, $M y d 88^{-/-}$, and $\operatorname{Tr} 9^{-/-}$pDCs were infected with AAV2-GFP, AAV1-GFP, or AAV9-GFP and examined for the secretion of IFN- $\beta$. Although WT pDCs infected with AAV1-GFP (Figure 5D) or AAV9-GFP (Figure 5E) produced lower levels of IFN- $\beta$ than those infected with AAV2-GFP (Figure 5C), our data showed that, similar to AAV2-GFP (Figure 5C), no type I IFN secretion was detected in $\operatorname{Tl} 9^{-/-}$or $M y d 88^{-/-}$pDCs upon stimulation with AAV1-GFP (Figure 5D) or AAV9-GFP (Figure 5E). These results suggest that innate immune activation by other AAV serotypes is also dependent on the TLR9-MyD88 pathway.

The TLR9-MyD88 pathway is critical for $C D 8^{+} T$ cell responses to the transgene product and the $A A V$ capsid, and for the loss of transgene expression in vivo. We next determined the biological significance of the TLR9-MyD88 pathway in adaptive immune responses to AAV vectors in vivo. To address this question, we utilized a murine model of skeletal muscle-mediated gene transfer because the skeletal muscle is widely considered to be a target for AAV-mediated gene therapy in vivo. AAV2-HA was injected intramuscularly into

\section{Figure 5}

Activation of the TLR9-MyD88 pathway by AAV is independent of the nature of the transgene or AAV serotypes. pDCs $\left(1 \times 10^{6}\right)$ generated from WT, Myd88 ${ }^{-/-}$, or T/r9-/- mice were stimulated with $2 \times 10^{10} \mathrm{vg}$ of AAV2-lacZ (A), AAV2-HA (B), AAV2-GFP (C), AAV1-GFP (D), or AAV9-GFP (E) for 18 hours, and the supernatants were assayed for the secretion of IFN $-\beta$ by ELISA. Representative data of 3 independent experiments are shown.

WT, Tlr9-/-, or $M y d 88^{-/-}$BALB/c mice. Twelve days later, high levels of HA expression were detected in the skeletal muscles of all mice (Figure 6A). However, the transgene expression was transient, as HA expression was significantly reduced by day 26 after injection and completely cleared by day 60 (Figure 6A). This was consistent with the previous observation that AAV-mediated HA expression in skeletal muscles of BALB/c mice is transient (19). In contrast, the HA expression was stable in Tlr9-/- (Figure 6A) and $M y d 88^{-/-}$(data not shown) mice. At day 26, splenocytes were analyzed for virus-specific $\mathrm{T}$ cell activation using the standard $\mathrm{T}$ cell proliferation assay, with ${ }^{3} \mathrm{H}$-thymidine incorporation upon in vitro restimulation with different doses of AAV2-HA. In WT mice, AAV infection resulted in robust $\mathrm{T}$ cell activation, whereas in $\mathrm{Tl} \mathrm{P}^{-/-}$or Myd88 $8^{-1-}$ mice, $\mathrm{T}$ cell activation was significantly diminished $(P<0.001$; Figure 6B). These results suggest that the TLR9-MyD88 pathway is critical for the activation of AAV-specific T cells, leading to the loss of transgene expression in vivo.

Since the proliferation assay measures total $\mathrm{T}$ cell responses to $\mathrm{AAV}$, we further examined cytotoxic $\mathrm{CD}^{+} \mathrm{T}$ cell responses to the HA transgene and the AAV2 capsid using an IFN- $\gamma$ intracellular staining assay upon in vitro restimulation with immunodominant epitope peptides specific for HA and the AAV capsid, respectively. In WT mice, AAV infection resulted in activation of both capsidand HA-specific $\mathrm{CD}^{+} \mathrm{T}$ cell responses, but with different kinetics: robust capsid-specific $\mathrm{CD}^{+} \mathrm{T}$ cell response was observed at both days 12 and 26 (Figure 6, C and D), whereas high levels of HA-specific $\mathrm{CD}^{+} \mathrm{T}$ cells were detectable only at day 26 (Figure 6, E and F). This difference in kinetics may reflect availability of different antigens for presentation by DCs - AAV-mediated transgene expression in vivo usually takes $1-2$ weeks, whereas the input AAV capsid is readily available upon viral infection. Despite this difference, in Tlr9-/- or $\mathrm{Myd}^{-18^{-/}}$mice, $\mathrm{CD}^{+} \mathrm{T}$ cell responses to both the AAV capsid (Figure 6, C and D) and HA (Figure 6, E and F) were significantly $(P<0.001)$ diminished compared with the WT control. This was associated with a reduction in $\mathrm{CD}^{+} \mathrm{T}$ cell infiltration into the infected muscles of $T \operatorname{lr} 9^{-/-}$or $M y d 88^{-/-}$mice compared with the WT group (Supplemental Figure 3). These results indicate that an intact TLR9-MyD88 pathway is required for the activation of AAV capsid- and transgene product-specific $\mathrm{CD}^{+} \mathrm{T}$ cells and the loss of transgene expression in vivo.

The transgene-specific and $A A V$-neutralizing antibody responses are also dependent on the TLR9-MyD88 pathway. We next investigated whether the TLR9-MyD88 pathway also influenced an adaptive B cell response to AAV infection. WT, $\operatorname{Tr} 9^{-/-}$, and $M y d 88^{-1-}$ mice were injected intramuscularly with $1 \times 10^{11} \mathrm{vg}$ of AAV2-HA, and serum samples were harvested 36 days later and assayed for the presence of anti-HA antibody and the neutralizing antibody to AAV. Sera from WT mice infected with AAV2-HA were found to 
A

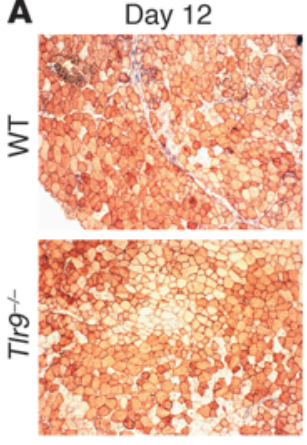

Day 26

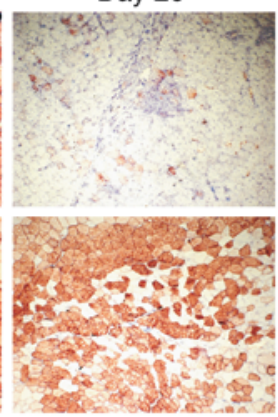

Day 60

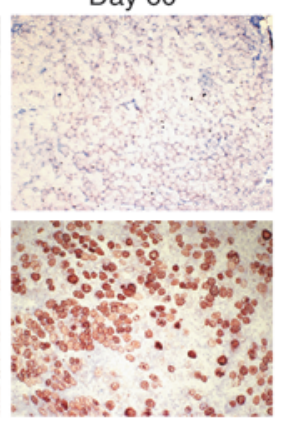

B

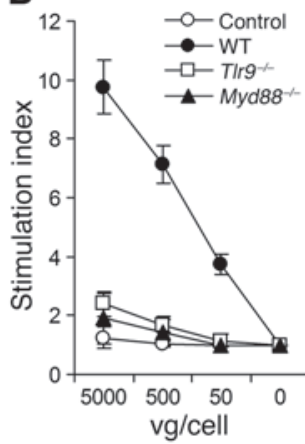

C

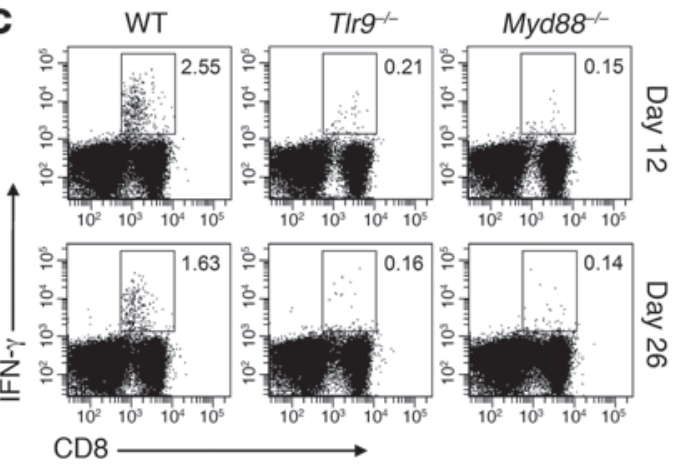

E

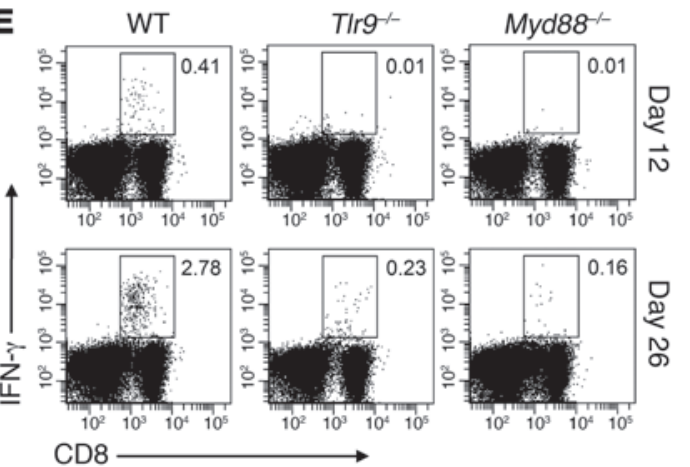

D

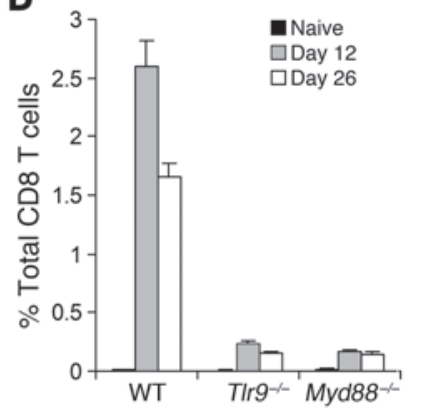

$\mathbf{F}$

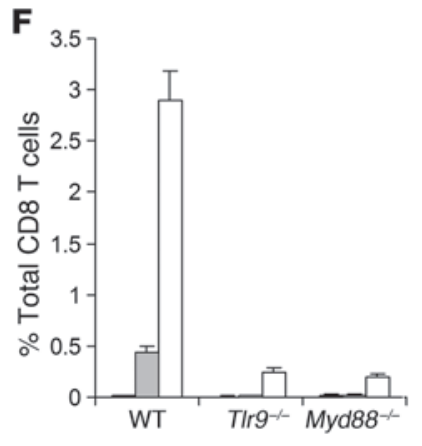

\section{Figure 6}

Lack of TLR9-MyD88 signaling diminishes CD8 ${ }^{+} \mathrm{T}$ cell responses to the AAV capsid and the transgene product and prolongs the transgene expression. AAV2-HA $\left(1 \times 10^{11}\right.$ $\mathrm{vg}$ ) was injected intramuscularly into $\mathrm{WT}$, Tlr9-/-, or Myd88-/- BALB/c mice. (A) After 12,26 , and 60 days, the infected muscles were harvested and analyzed for HA expression by immunohistochemistry. Original magnification, $\times 100$. (B) $\mathrm{CD}^{+}$ T cells purified from splenocytes at day 26 after infection, along with uninfected WT splenocytes (control), were restimulated with AAV2-HA at $0,50,500$, or $5,000 \mathrm{vg} /$ cell. Proliferation of AAV-specific T cells was analyzed by ${ }^{3} \mathrm{H}$-thymidine incorporation. Data reflect the mean $\pm S D$ of the stimulation index, which was calculated by dividing ${ }^{3} \mathrm{H}$ counts in $\mathrm{cpm}$ in the presence of viral stimulation by those in the absence of stimulation, as a function of different virus doses. (C-F) At days 12 and 26 after infection, splenocytes were harvested and stimulated with either AAV2 capsid epitope peptide ( $\mathbf{C}$ and $\mathbf{D}$ ) or HA epitope peptide ( $E$ and $\mathbf{F}$ ) for 5 hours and assayed for intracellular IFN- $\gamma$ secretion by $\mathrm{CD}^{+}$ T cells. (C and E) The FACS plots show percentages of IFN- $\gamma$-producing CD8 ${ }^{+} \mathrm{T}$ cells among total CD8 ${ }^{+} T$ cells. (D and $\mathbf{F}$ ) The mean percentages \pm SD of IFN- $\gamma$-producing $\mathrm{CD}^{+} \mathrm{T}$ cells among total $\mathrm{CD} 8^{+} \mathrm{T}$ cells are also shown. Representative results of 3 independent experiments are shown. contain high titers of anti-HA antibody (Figure 7A) and neutralizing antibody to AAV (Figure 7B). However, both the anti-HA antibody response (Figure $7 \mathrm{~A}$ ) and neutralizing antibody titers (Figure 7B) were significantly $(P<0.001)$ diminished in AAV2-HA-infected Tlr $9^{-{ }^{-}}$and $\mathrm{Myd} 88^{-{ }^{-}}$mice compared with the WT control. We further analyzed AAV vector-specific Ig isotypes by ELISA. The results revealed that a similar degree of reduction in AAV-specific IgG2a (indicative of Th1-dependent B cell response) titers in $\operatorname{Tl} 9^{-/-}$and Myd88 ${ }^{-/-}$mice, compared with the WT control (Figure 7C). However, only moderate reduction of AAV-specific IgG1 (indicative of a Th2-dependent B cell response; Figure 7D) and IgG3 (indicative of a Th-independent B cell response; Figure 7E) titers was noted in $\operatorname{Tl} 9^{-/-}$and $M y d 88^{-/-}$mice. Thus, the formation of transgenespecific and AAV-neutralizing antibodies is also dependent on an intact TLR9-MyD88 signaling pathway.

Type I IFNs are required for adaptive immune responses to $A A V$. How does the TLR9-MyD88 innate immune pathway regulate adaptive immune responses to AAV? The TLR9-dependent production of mainly type I IFNs by pDCs upon AAV infection suggested that type I IFNs may play a key role in promoting adaptive immune responses to AAV in vivo. To test this hypothesis, we examined whether adaptive immune responses to AAV were dependent on type I IFNs. AAV2-HA $\left(1 \times 10^{11} \mathrm{vg}\right)$ was injected intramuscularly into WT mice or mice deficient for the IFN- $\alpha$ and IFN- $\beta$ receptor $\left(\right.$ If $\left.n r^{--}\right)$and examined for HA expression 12 and 36 days after injection. High levels of HA expression were detected in the skeletal muscles of WT and Ifnr ${ }^{-1}$ mice 12 days after infection (Figure 8A). By day 36, a significant loss of HA-expressing muscle fibers was detected in WT mice. By contrast, the expression of HA remained stable in Ifnr ${ }^{-/}$mice (Figure $8 \mathrm{~A}$ ). This corresponded to a significant $(P<0.001)$ reduction in AAV-specific T cell activation in Ifnr-/mice compared with the WT control (Figure 8B). In addition, both anti-HA antibody (Figure 8C) and AAV-neutralizing antibody (Figure 8D) titers were significantly $(P<0.001)$ diminished in Ifnr ${ }^{--}$ mice. Taken together, these data indicate that type I IFNs play a pivotal role in the TLR9-MyD88-dependent adaptive immune responses to $\mathrm{AAV}$ vectors in vivo.

$A A V$ also activates human pDCs in a TLR9-dependent manner. The critical role for the TLR9-MyD88 pathway in innate and adaptive immune responses to AAV vectors suggested that strategies to 

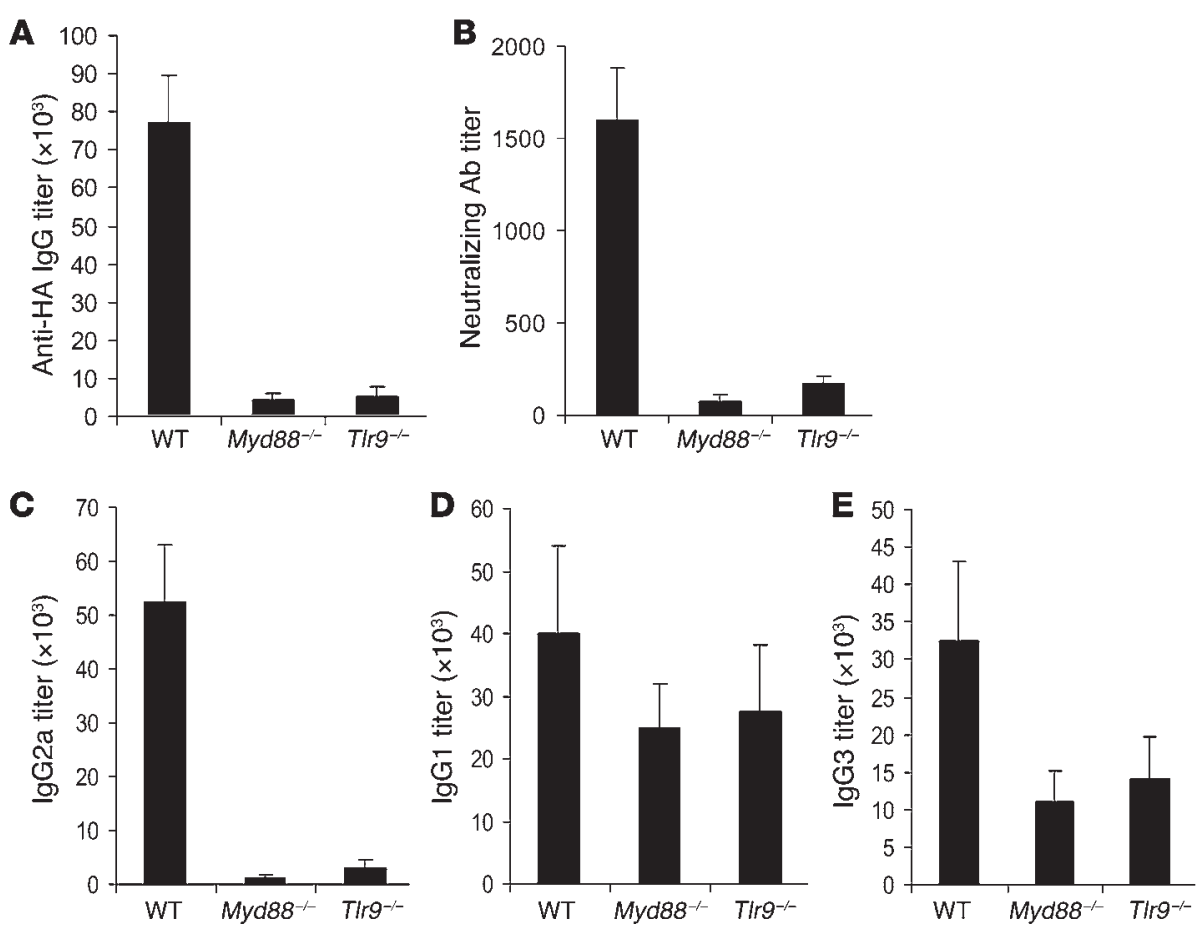

\section{Figure 7}

The formation of anti-transgene and AAVneutralizing antibodies is also dependent on the TLR9-MyD88 pathway. WT, TIr9-1-,

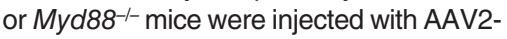
HA intramuscularly. (A and B) Serum samples were harvested at day 36 for the measurement of anti-HA antibody titer by ELISA (A) as well as neutralizing antibody titers to AAV vectors (B). (C-E) Sera were also analyzed for vector-specific IgG2a (C), IgG1 (D), and IgG3 (E) by ELISA. Data reflect the mean $\pm S D$ of reciprocal endpoint titers. Data shown are representative of 3 independent experiments. interfere with the TLR9-MyD88 pathway may improve the outcome of AAV-mediated gene therapy in humans. As a first step to testing this strategy, we examined whether AAV also activated human pDCs via TLR9. Human $\mathrm{pDCs}$ and monocytes were purified from PBMCs and stimulated with AAV2-lacZ for 18 hours. Cells were then harvested and total RNA was examined for the expression of human IFN- $\alpha$ (hIFN- $\alpha$ ) and hIFN- $\beta$ by RT-PCR. Consistent with the observation in mice, AAV-stimulated human $\mathrm{pDCs}$, but not non-pDCs such as monocytes, induced the expression of hIFN- $\alpha$ and hIFN- $\beta$ (Figure 9A). To test whether activation of human $\mathrm{pDCs}$ by AAV was also mediated by TLR9, purified pDCs were pretreated with a TLR9 antagonist, H154 oligodeoxynucleotide (ODN) (33), followed by stimulation with AAV2-lacZ, and cellular RNA was analyzed for the induction of hIFN- $\alpha$ and hIFN- $\beta$ by semi-quantitative RT-PCR. Our data showed that pretreatment with H154 ODN completely blocked the induction of hIFN- $\alpha$ and hIFN- $\beta$ upon AAV infection, compared with untreated controls (Figure 9B). Similarly, pretreatment with $\mathrm{H} 154 \mathrm{ODN}$ also abrogated the induction of hIFN- $\alpha$ and hIFN- $\beta$ by a TLR9 agonist, CpG-A ODN (34), confirming the specificity of TLR9 blocking by H154 ODN (Figure 9B). These results indicate that the activation of human pDCs by AAV is also mediated by TLR9 and suggest a strategy for TLR9 blockade to blunt AAV-induced innate immune response.

\section{Discussion}

The adaptive immune responses to AAV represent a significant hurdle in the clinical application of AAV vectors for gene therapy. Recent developments have suggested a critical role for the innate immunity in promoting adaptive immune responses. A major unanswered question is how AAV activates the innate immune pathway. In this study, we demonstrated that AAV activated pDCs, but not non-DCs such as CDCs and macrophages, to produce type I IFNs through the TLR9-MyD88 pathway. In vivo, the TLR9MyD88 innate immune pathway was required for the activation of
$\mathrm{CD}^{+} \mathrm{T}$ cell responses to both the transgene product and the AAV capsid, leading to the loss of transgene expression. Furthermore, the formation of antibodies to the transgene product and the AAV vector was also critically dependent on this pathway. In addition, we showed that TLR9-dependent activation of adaptive immune responses to AAV was mediated by type I IFNs and that AAV also activated human pDCs to induce type I IFNs via TLR9.

Our finding that, similar to adenoviral vectors, AAV predominantly activated PDCs via the TLR9-MyD88 pathway to secrete type I IFNs is in line with previous observations that pDCs are the most potent type I IFN producers and secrete mainly type I IFNs upon TLR9 stimulation $(31,35)$. The mechanism(s) underlying this pDC-specific involvement of the TLR9-MyD88-type I IFN pathway remains incompletely defined. Studies have shown that stimulation of TLR9 with CpG DNA in pDCs activates MyD88, which then interacts with IRAK1 and TRAF6, leading to the activation of IKK $\alpha$ and IRF7 and the production of type I IFNs $(36,37)$. However, this pathway is not operative in non-pDCs such as cDCs. Furthermore, pDCs express high levels of IRF7 and osteopontin, both of which are critical for the induction of type I IFNs $(38,39)$. In addition, CpG DNAs are retained longer in pDC endosomes where TLR9 resides, but are rapidly transferred to lysosomes for degradation in non-pDCs $(40,41)$. Indeed, we have found that pDCs are poorly transduced by adenoviral vectors (31), which may be related to the preferential retention of $\mathrm{CPG}$-containing viral DNA in the endosome.

The TLR9-dependent recognition of AAV also suggests that the ligand for TLR9 recognition is viral DNA. How is the encapsidated single-stranded AAV DNA exposed in endosomes for its recognition by TLR9? It has been shown that following clathrin-dependent or -independent internalization, transducing AAV is routed through the endosomal compartment, where $\mathrm{pH}$-dependent penetration of endosomes by the virus occurs (42). Studies with other viruses have suggested that the highly acidified endosomal 
A
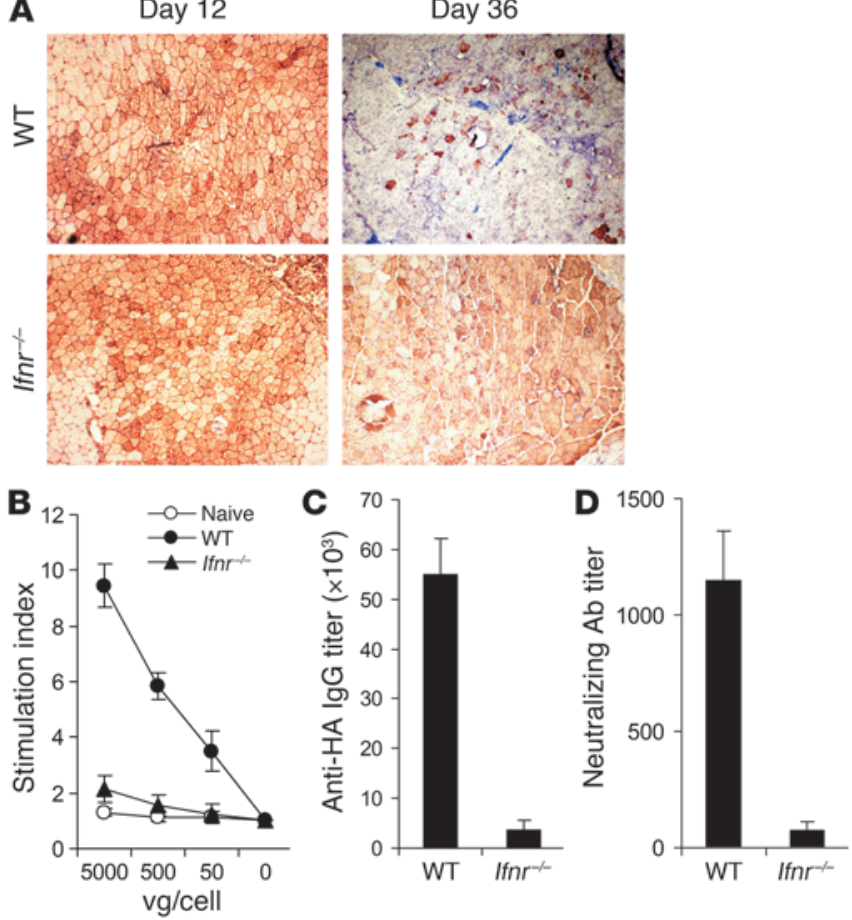

\section{Figure 8}

Type I IFNs play a critical role in adaptive immune responses to AAV. AAV2-HA was injected intramuscularly into WT or Ifnr-1- mice. (A) After 12 and 36 days, the infected muscles were harvested and analyzed for $\mathrm{HA}$ expression by immunohistochemistry. Original magnification, $\times 100$. (B) $C D 5^{+} T$ cells purified from splenocytes at day 36 after infection, along with uninfected WT splenocytes (naive), were restimulated with AAV2-HA at $0,50,500$, or $5,000 \mathrm{vg} /$ cell. Proliferation of AAV-specific $\mathrm{T}$ cells was analyzed by ${ }^{3} \mathrm{H}$-thymidine incorporation. Data reflect the mean \pm SD of the stimulation index, which was calculated by dividing ${ }^{3} \mathrm{H}$ counts in $\mathrm{cpm}$ in the presence of viral stimulation by those in the absence of stimulation, as a function of different virus doses. (C and D) Serum samples were harvested at day 36 for the measurement of anti-HA (C) and AAV-neutralizing (D) antibody titers. Data shown are representative of 2 independent experiments. compartment, which contains abundant proteolytic degradation enzymes, may damage viral particles and release some viral DNA for recognition by TLR9 $(30,43)$. This process is independent of viral transduction, and viruses that do not normally replicate in pDCs, as well as defective viral particles or inactivated virus, can also be detected. Even viruses neutralized by antibody or complement can be taken up via Fc or complement receptors and subject to TLR recognition within endosomes (44). Similar to AAV2, other serotypes of AAV, including AAV1 and AAV9, also activate pDCs via the TLR9-MyD88 pathway. However, $\mathrm{pDCs}$ infected with AAV1 or AAV9 appear to induce lower levels of type I IFNs than those with AAV2, suggesting that different serotypes of AAV may differ in activating the innate immune system. It remains to be defined whether this reflects a difference in endosome targeting and/or processing of AAV. Thus, further investigation is needed to define endosomal sensing of AAV by TLR9.

Whether capsid components of AAV can activate innate immune responses is unknown. A recent report has suggested that complement components might interact with AAV capsids to enhance

Figure 9

Activation of human pDCs by AAV is also mediated by TLR9. (A) Human pDCs or monocytes $\left(1 \times 10^{5}\right)$ were purified from PBMCs and stimulated with AAV2-lacZ $\left(2 \times 10^{9} \mathrm{vg}\right)$ or left unstimulated for 18 hours. Cells were then harvested, and total RNA was treated with DNase I and assayed for the expression of hIFN- $\alpha$ and hIFN- $\beta$ by RT-PCR. (B) Human pDCs $\left(1 \times 10^{5}\right)$ were either unstimulated or stimulated with AAV2-lacZ $\left(2 \times 10^{9} \mathrm{vg}\right)$ or a TLR9 agonist, CpG-A ODN $(5 \mu \mathrm{g} / \mathrm{ml})$. In some experiments, cells were pre-treated with the TLR9 antagonist H154 ODN $(10 \mu \mathrm{M})$ for 30 minutes, followed by stimulation with AAV2-lacZ or CpG-A. After 18 hours, cellular RNA was analyzed for the induction of hIFN- $\alpha$ and hIFN- $\beta$ by semi-quantitative RT-PCR using 5 -fold serial dilution of the template. Human ribosomal protein S14 was used as an internal loading control. Data shown are representative of 2 independent experiments. the stimulation on macrophages by AAV in vitro (45). However, cytokine secretion upon AAV infection is not compromised in mice deficient for complement components in vivo, suggesting that such an interaction may not exist in vivo (45). Thus, the role of complement components in innate immune response to AAV in vivo remains uncertain.

The observation that very low levels of type I IFNs and proinflammatory cytokines were produced by non-pDCs upon AAV infection is in striking contrast to adenoviral vectors. Since production of proinflammatory cytokines and type I IFNs by pDCs stimulated with adenoviral vectors is mediated by a TLR-independent pathway through cytosolic sensing of double-stranded adenoviral DNA $(31,46)$, these data suggest that the single-stranded AAV genome may not activate this pathway efficiently in nonpDCs. Indeed, it is believed that the ligand for the yet-to-be-identified cytosolic DNA sensor is double-stranded B-form DNA derived from many microbes $(47,48)$. The very low levels of cytokines produced by non-pDCs upon AAV infection may explain a lack of strong inflammatory responses documented in numerous models
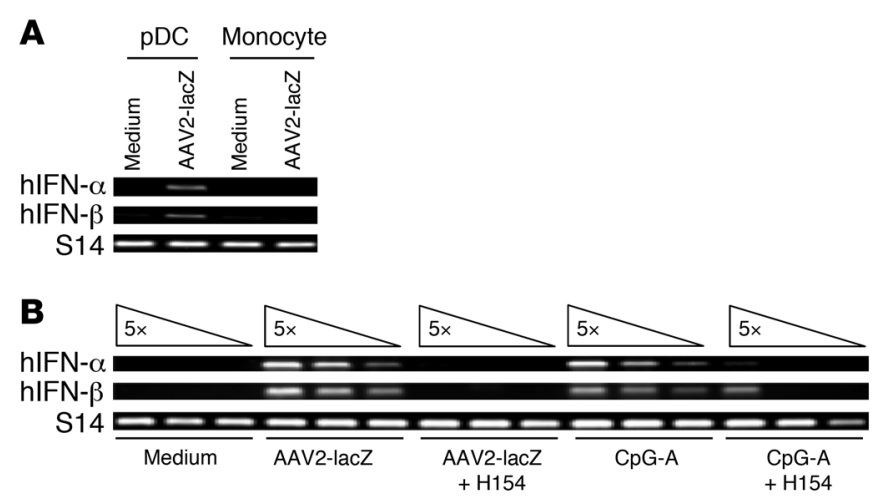
of AAV-mediated gene therapy in vivo (49). As pDCs mainly reside in the spleen and other secondary lymphoid organs (35), the lack of strong type I IFN or proinflammatory cytokine responses from non-pDCs upon AAV infection may also explain a recent observation that robust transcriptome responses, including the induction of a cluster of type I IFN-related genes, associated with adenoviral vectors by microarray analysis of liver RNA were not observed with $\mathrm{AAV}$ vectors (50). Taken together, the above observations are consistent with the notion that AAV is a weak immunogen compared with adenoviral vectors.

The biological significance of the TLR9-MyD88-type I IFN pathway in innate sensing of AAV by pDCs lies in its critical role in the activation of adaptive $\mathrm{T}$ and $\mathrm{B}$ cell responses to the transgene product and the AAV vector. Our results indicate that an intact TLR9-MyD88 pathway is required for the activation of both AAV capsid- and transgene product-specific $\mathrm{CD}^{+} \mathrm{T}$ cells. The lack of $\mathrm{CD}^{+} \mathrm{T}$ cell responses early after infection (day 12 ) in $\mathrm{Tl} \mathrm{V}^{-{ }^{-}-}$or Myd88 $8^{-/-}$mice suggests that the TLR9-MyD88 pathway is critical for $\mathrm{CD}^{+} \mathrm{T}$ cell priming. The observation that the kinetics of transgene-specific $\mathrm{CD}^{+} \mathrm{T}$ cell response is closely associated with the loss of transgene expression (Figure 6, A, E, and F), suggests that transgene-specific $\mathrm{CD}^{+} \mathrm{T}$ cells may be critical for the elimination of the transduced cells in vivo. This is very similar to a recent observation that lentiviral vectors activate $\mathrm{PDCs}$ via TLR7 to secrete type IFNs, which is required for subsequent activation of CTLs against the transgene product (51). However, since the TLR9 pathway also regulates the activation of capsid-specific $\mathrm{CD}^{+} \mathrm{T}$ cells, we can not rule out the role of capsid-specific $\mathrm{T}$ cells in eliminating AAVtransduced cells in vivo.

The mechanism(s) underlying type I IFN-dependent adaptive immune responses to AAV requires further investigation. Studies in other models have shown that type I IFNs can promote DC maturation and function $(52,53)$. Type I IFNs have also been shown to enhance cross-presentation by DCs (54). This observation is particularly relevant to AAV infection, since the activation of both transgene- and viral capsid-specific CTL responses are thought to be dependent on cross-presentation by MHC class I (15, 19-23). Furthermore, we have recently shown that direct type I IFN signaling is required for the survival of activated $T$ cells in response to vaccinia viral infection (55). Type I IFNs are also critical for multiple stages of adaptive $B$ cell response to adenovirus, and the generation of protective neutralizing antibodies to adenovirus critically depends on type I IFN signaling on both CD4 T cells and B cells (56). Thus, future studies should focus on defining mechanisms by which type I IFNs promote adaptive immune responses to AAV.

Our observation that human pDCs can also be activated by AAV to induce type I IFNs via TLR9 suggests that the TLR9 pathway might also be important in regulating adaptive immune responses to AAV in humans. However, studies have shown that the induction of adaptive immune responses to AAV is influenced by many factors, including host species and a pre-existing immunity to AAV (18). Thus, additional studies in nonhuman primates as well as in human clinical trials are required to define the role of the TLR9 innate immune pathway in the activation of adaptive immune responses to AAV in humans.

The route of administration has also played a role in adaptive immune responses to AAV. Studies in murine models have shown that hepatic delivery of AAV often results in immune tolerance to the transgene product $(57,58)$. It is not clear whether this is a result of defective innate immune activation in the liver (e.g., insufficient pDCs or lack of interaction of AAV with pDCs), the existence of immunosuppressive cell types such as regulatory $\mathrm{T}$ cells and Kupffer cells, and/or the existence of immunosuppressive cytokines such as IL-10 in the hepatic microenvironment (59, 60). Thus, it will be important to delineate factors that influence immune responses to AAV in the liver.

In conclusion, our study reveals that $\mathrm{AAV}$ activates the innate immunity through the TLR9-MyD88 pathway in PDCs, which leads to the production of type I IFNs. In vivo, this innate immune pathway plays a critical role in the activation of $\mathrm{CD}^{+} \mathrm{T}$ cell responses to both the transgene product and the AAV capsid and the formation of anti-transgene and AAV-neutralizing antibodies. Furthermore, AAV also activates human pDCs to produce type I IFNs in a TLR9-dependent fashion. These results suggest that strategies targeted to interfere with the TLR9-MyD88-type I IFN signaling pathway may improve the safety and efficacy of AAV vectors for gene therapy in humans.

\section{Methods}

Mice. C57BL/6 and BALB/c mice were purchased from The Jackson Laboratory. $\operatorname{Tl} 2^{-/-}, \operatorname{Tl} 9^{-/-}, \mathrm{Myd} 88^{-/-}$, and Trif/- mice on a C57BL/6 background were kindly provided by Shizuo Akira (Osaka University, Osaka, Japan). IFN- $\alpha \beta \mathrm{R}^{-/-}$mice (61) on a $129 / \mathrm{Sv}$ background and their normal control

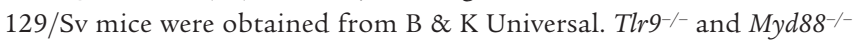
mice had been backcrossed onto BALB/c background for more than 9 generations in our animal facility. Groups of 7- to 10-week-old mice were selected for this study. All experiments involving the use of mice were done in accordance with protocols approved by the Animal Care and Use Committee of Duke University.

Recombinant AAV. Recombinant AAV2-HA, AAV2-lacZ, or AAV2-GFP under the control of CMV promoter were generated with a helper virusfree system (Stratagene) by transfecting 293 cells (which stably express the adenovirus E1 gene) with 3 plasmids as previously described $(62,63)$. These 3 plasmids were pHelper, encoding the E2A, E4, and VA RNA genes of adenovirus; pAAV-RC, encoding the AAV2 rep and cap genes; and vector plasmid PAAV-CMV-HA, -lacZ, or -GFP. Purification of AAV was done by heparin affinity chromatography, as described previously (32). Briefly, cells were disrupted by freezing and thawing 2 times, and cell lysates were incubated with $40 \mu \mathrm{g} / \mathrm{ml}$ of DNase I and RNase A (Roche Biochemicals) for 30 minutes at $37^{\circ} \mathrm{C}$. After centrifugation, the supernatants were then incubated with $0.5 \%$ deoxycholic acid (Sigma-Aldrich) for 30 minutes at $37^{\circ} \mathrm{C}$, followed by filtration through a $5-\mu \mathrm{m}$ and a $0.8-\mu \mathrm{m}$ pore size filter (Millipore) sequentially. The cleared supernatants were then loaded onto a heparin column. After washing twice with PBS, pH 7.4, plus $0.1 \mathrm{M} \mathrm{NaCl}$, the virus was eluted with PBS, $\mathrm{pH} 7.4$, plus $0.4 \mathrm{M} \mathrm{NaCl}$. The eluate was concentrated with a Millipore Biomax-100K NMWL filter device by centrifugation. The vg titer was determined with a CMV promoter-specific quantitative real-time PCR procedure.

For the production of recombinant AAV1-GFP and AAV9-GFP, pAAVCMV-GFP and pHelper were cotransfected into 293 cells along with a chimeric packaging plasmid, in which the AAV2 rep gene was fused to AAV1 and AAV9 capsid genes, respectively. Cells were harvested, sonicated, and treated with DNase I and RNase A. The resultant AAV1-GFP and AAV9GFP viral particles were purified twice by $\mathrm{CsCl}$ density gradient ultracentrifugation, as described previously (64).

Murine DC culture. pDCs were generated as previously described (31). Briefly, bone marrow cells were harvested from femurs and tibias of mice and cultured in the presence of $200 \mathrm{ng} / \mathrm{ml}$ of Flt-3 ligand (R\&D Systems) for 9 days. For generation of cDCs, bone marrow cells were cultured in the presence of mouse GM-CSF $(1,000 \mathrm{U} / \mathrm{ml})$ and IL-4 (500 U/ml) (R\&D 
Systems) for 5 days, as previously described (65). pDCs and cDCs were stained with anti-B220-FITC and anti-CD11c-PE and purified by FACS sorting. Purified cells were then stimulated with various agents at a density of $1 \times 10^{6}$ cells $/ \mathrm{ml}$.

Isolation of murine splenic DCs, macrophages, and Kupffer cells. Splenic DC isolation was performed as previously described (31). After perfusion with Liberase CI (Roche Biochemicals), single-cell suspensions were subjected to $30 \%$ BSA gradient, and the interface DC fraction was collected and stained with anti-B220-FITC and anti-CD11c-biotin, followed by streptavidin microbeads (Miltenyi Biotec). CD11 $\mathrm{c}^{+} \mathrm{DCs}$ were purified by positive selection by microbeads and subjected to FACS sorting into $\mathrm{pDCs}$ $\left(\mathrm{CD} 11 \mathrm{c}^{+} \mathrm{B} 220^{+}\right)$and $\mathrm{cDCs}\left(\mathrm{CD} 11 \mathrm{c}^{+} \mathrm{B} 220^{-}\right)$. Macrophages were isolated from the peritoneal cavity of mice 3 days after intraperitoneal injection of $2.5 \mathrm{ml}$ of $3 \%$ thioglycollate as previously described (66). Kupffer cells were isolated from mouse livers as described (31). After perfusion in situ via portal vein with collagenase, single-cell suspensions were subjected to gradient centrifugation with $11.5 \%$ OptiPrep solution. Kupffer cell fraction was collected from the interface and purified by FACS sorting for $\mathrm{F} 4 / 80^{+}$ cells. Purified splenic CD11 $c^{+}$DCs, macrophages, and Kupffer cells were stimulated with various agents at a density of $2.5 \times 10^{5} \mathrm{cells} / \mathrm{ml}$.

Detection of cytokines by ELISA. Production of IL- 6 , TNF- $\alpha$, IFN- $\alpha$, and IFN- $\beta$ by DCs in response to various stimuli was detected in cultured supernatants by ELISA kits according to the manufacturer's standard protocols. IL- 6 and TNF- $\alpha$ ELISA kits were purchased from Endogen (Pierce Biotechnology). IFN- $\alpha$ and IFN- $\beta$ kits were obtained from PBL Biomedical Laboratories.

In vivo delivery of recombinant AAV. AAV-HA $\left(1 \times 10^{11} \mathrm{vg}\right)$ in $25 \mu$ l of PBS, $\mathrm{pH}$ 7.4 , was injected into tibialis anterior muscles of mice. Mice were sacrificed at different time points for histological and immunological assays. All animals that received recombinant virus survived to the time of necropsy.

Proliferation assay. T cells were isolated from splenocytes using CD5 microbeads (Miltenyi Biotec). $\mathrm{CD}^{+} \mathrm{T}$ cells $\left(2 \times 10^{5}\right)$ were cocultured with irradiated $(3,000 \mathrm{rad})$ naive splenocytes $\left(2 \times 10^{5}\right)$ in the presence of AAV2$\mathrm{HA}$ at $0,50,500$, or $5,000 \mathrm{vg} /$ cell for 72 hours, in triplicate. Cultures were pulsed with $1 \mu \mathrm{Ci}$ per well of ${ }^{3} \mathrm{H}$-thymidine. About $16-20$ hours after pulsing, plates were harvested using a 96-well cell harvester, and the ${ }^{3} \mathrm{H}$-thymidine incorporation was counted using a 1205 Betaplate scintillation counter (Wallac).

Antibodies and flow cytometry. All antibodies used for FACS were purchased from BD Biosciences. FACSCanto (BD Biosciences) was used for flow cytometry event collection, and data were analyzed using FACS DIVA and CELLQuest software (BD Biosciences).

For intracellular IFN- $\gamma$ staining, splenocytes were stimulated with $2 \mu \mathrm{g} / \mathrm{ml}$ of L $L^{\mathrm{d}}$-restricted AAV2 capsid epitope peptide (372VPQYGYLTL ${ }^{380}$ ) (67) or $\mathrm{K}^{\mathrm{d}}$-restricted HA epitope peptide ( ${ }^{518}$ IYSTVASSL $\left.^{526}\right)$ (65), and $5 \mu \mathrm{g} / \mathrm{ml}$ of GolgiPlug (BD Biosciences) for 5 hours. After washing, cells were stained with anti-CD8 ${ }^{+}$(clone 53-6.7) and permeabilized to detect IFN- $\gamma$ intracellularly with anti-IFN- $\gamma$ (clone XMG1.2) using the Cytofix/ Cytoperm kit (BD Biosciences) as previously described (65).

Immunohistochemical staining. Frozen sections $(5 \mu \mathrm{m})$ of muscles were fixed with acetone, air dried, and rehydrated in PBS. After blocking with 20\% goat serum in PBS, sections were incubated with biotinylated anti-HA or anti-CD8 ${ }^{+} \mathrm{mAb}$, followed by staining using an ABC kit (Vector Laboratories), as previously described (68).

Neutralizing antibody assay. Neutralizing antibody titers were analyzed by assessing the ability of serum antibody to inhibit transduction of AAV2lacZ into AAV permissive HT1080 cell line. HT1080 cells (60\%-70\% confluent $)$ in 96-well plates $\left(2 \times 10^{4}\right.$ cells per well) were treated with $0.2 \mathrm{ml}$ of $240 \mathrm{mM}$ of hydroxyurea and $3 \mathrm{mM}$ of sodium butyrate for 6 hours at $37^{\circ} \mathrm{C}$. Serum samples were incubated at $56^{\circ} \mathrm{C}$ for 30 minutes and then diluted in 2-fold steps starting from 1:20 or 1:50. Serial dilutions of sera were pre-incubated with $2.5 \times 10^{8} \mathrm{vg}$ of AAV2-lacZ in a $100-\mu \mathrm{l}$ total volume for 1 hour at $37^{\circ} \mathrm{C}$ and added to pretreated cell cultures. Cells were fixed and analyzed for lacZ expression by $\mathrm{X}$-gal staining on the following day, as previously described (56). All of the cells stained blue in the absence of serum samples. The titer of neutralizing antibody for each sample was reported as the highest dilution with which less than $50 \%$ of cells stained blue.

AAV2-specific antibody isotyping by ELISA. Serum samples were analyzed for AAV2-specific Ig isotypes (IgG1, IgG2a, and IgG3) by ELISA as previously described, with some modifications (56). Briefly, 96-well plates (Costar) were coated with AAV2-lacZ $\left(1 \times 10^{9} \mathrm{vg} / \mathrm{ml}\right)$ in $100 \mu \mathrm{l} 0.1 \mathrm{M}$ carbonate (pH 9.6) overnight at $4{ }^{\circ} \mathrm{C}$. Serial diluted samples were added to antigencoated plates and incubated for 2 hours. Plates were washed and incubated with biotin-conjugated goat anti-mouse IgG1, IgG2a, and IgG3 (Southern Biotech) for 1 hour. Horseradish peroxidase-coupled streptavidin (100 $\mu \mathrm{l}$; BD Biosciences) was then added. Finally, $100 \mu \mathrm{l}$ per well of the substrate solution (TMB; BD Biosciences) was added, and the substrate conversion was stopped by the addition of $100 \mu \mathrm{l}$ per well of $2 \mathrm{~N} \mathrm{HCl}$. Absorbance was measured at $450 \mathrm{~nm}$. Results were expressed as reciprocal endpoint titers, as described in ref. 56.

Anti-HA antibody titer. To measure antibody response to HA transgene, HA-expressing Renca cells (Renca-HA cells), which express HA on the cell surface, were seeded on a flat 96-well plate. After overnight culture, cells were fixed for 10 minutes with $0.25 \%$ glutaraldehyde in PBS, $\mathrm{pH}$ 7.4. Plates were washed and blocked with PBS containing 10\% FBS for 2 hours. After washing, serial diluted samples were added and incubated for 2 hours. Plates were then washed and incubated with biotin-conjugated goat anti-mouse IgG (Southern Biotech) for 1 hour at room temperature. Plates were washed as described above, and TMB substrate solution (BD Biosciences) was added. After 15 minutes, color development was stopped by the addition of $\mathrm{HCl}$. Optical densities were read at $450 \mathrm{~nm}$ on a microplate reader. Results were expressed as reciprocal endpoint titers, as previously described (56).

Isolation and stimulation of human $\mathrm{pDCs}$. Human $\mathrm{pDCs}$ were purified from PBMCs of healthy donors under approval of the Duke University institutional review board, as previously described (69). Briefly, PBMCs were first depleted of non-pDCs (i.e., T cells, B cells, NK cells, myeloid DCs, monocytes, granulocytes, and erythroid cells) using a cocktail of biotinconjugated antibodies and anti-biotin microbeads (Miltenyi Biotec). The enriched $\mathrm{pDCs}$ were further purified by positive selection using microbeads against human pDC-specific antigen CD304 (BDCA-4/neuropilin-1; Miltenyi Biotec). By this 2 -step magnetic separation procedure, the purity of the isolated pDCs was more than $99 \%$. Monocytes were also purified from PBMCs with anti-CD14 microbeads (Miltenyi Biotec) for use as a control. The purified $\mathrm{pDCs}$ and monocytes $\left(5 \times 10^{4}\right)$ were stimulated with AAV2lacZ for 18 hours, and cells were harvested for total RNA preparation. The expression of hIFN- $\alpha$ and hIFN- $\beta$ was assessed by RT-PCR using primers as previously described (70) for hIFN- $\alpha$ (sense, $5^{\prime}$-GATGGCCGTGCTGGTGCTCA- ${ }^{\prime}$; antisense, $5^{\prime}$-TGATTTCTGCTCTGACAACCTCCC-3') and for hIFN- $\beta$ (sense, $5^{\prime}$-TTGAATGGGAGGCTTGAATA- $3^{\prime}$; antisense, $5^{\prime}$-CTATGGTCCAGGCACAGTGA-3'). Human ribosomal protein S14 (sense, 5'-GGCAGACCGAGATGAATCCTCA-3'; antisense, 5'-CAGGTCCAGGGGTCTTGGTCC-3') was used as an internal control. For TLR9blocking experiments, pDCs were pretreated with $10 \mu \mathrm{M}$ of H154 ODN for 30 minutes, followed by stimulation with AAV2-lacZ or CPG-A ODN. Both H154 ODN (5'-CCTCAAGCTTGAGGGG-3') and CPG-A ODN (5'-GGGGGACGATCGTCGGGGGG-3') were phosphorothioate-stabilized and synthesized by Integrated DNA Technologies.

Statistics. Results are expressed as mean \pm SD. Differences between groups were examined for statistical significance using the Student's $t$ test. 


\section{Acknowledgments}

We thank Shizuo Akira (Osaka University, Osaka, Japan) for providing Tlr2-/-, Tlr9-/-, Myd88-/-, and Trif /- mice. We also thank Jude Samulski and the Vector Core (Gene Therapy Center, University of North Carolina at Chapel Hill, Chapel Hill, North Carolina, USA) for providing AAV1-GFP and AAV9-GFP. This work was supported by grants from the NIH (CA111807 and CA047741).
Received for publication April 3, 2009, and accepted in revised form May 13, 2009.

Address correspondence to: Yiping Yang, Departments of Medicine and Immunology, Duke University Medical Center, Box 103005, Durham, North Carolina 27710, USA. Phone: (919) 668-0932; Fax: (919) 684-9594; E-mail: yang0029@mc.duke.edu.
1. Wu, Z., Asokan, A., and Samulski, R.J. 2006. Adenoassociated virus serotypes: vector toolkit for human gene therapy. Mol. Ther. 14:316-327.

2. Snyder, R.O., et al. 1999. Correction of hemophilia $\mathrm{B}$ in canine and murine models using recombinant adeno-associated viral vectors. Nat. Med. 5:64-70.

3. Herzog, R.W., et al. 1999. Long-term correction of canine hemophilia B by gene transfer of blood coagulation factor IX mediated by adeno-associated viral vector. Nat. Med. 5:56-63.

4. Kay, M.A., et al. 2000. Evidence for gene transfer and expression of factor IX in haemophilia B patients treated with an AAV vector. Nat. Genet. 24:257-261.

5. Manno, C.S., et al. 2006. Successful transduction of liver in hemophilia by AAV-Factor IX and limitations imposed by the host immune response. Nat. Med. 12:342-347.

6. Greelish, J.P., et al. 1999. Stable restoration of the sarcoglycan complex in dystrophic muscle perfused with histamine and a recombinant adeno-associated viral vector. Nat. Med. 5:439-443.

7. Gregorevic, P., et al. 2006. rAAV6-microdystrophin preserves muscle function and extends lifespan in severely dystrophic mice. Nat. Med. 12:787-789.

8. Song, S., et al. 1998. Sustained secretion of human alpha-1-antitrypsin from murine muscle transduced with adeno-associated virus vectors. Proc. Natl. Acad. Sci. U. S. A. 95:14384-14388.

9. Stedman, H., Wilson, J.M., Finke, R., Kleckner, A.L., and Mendell, J. 2000. Phase I clinical trial utilizing gene therapy for limb girdle muscular dystrophy: alpha-, beta-, gamma-, or delta-sarcoglycan gene delivered with intramuscular instillations of adenoassociated vectors. Hum. Gene Ther. 11:777-790.

10. Flotte, T.R., et al. 1993. Stable in vivo expression of the cystic fibrosis transmembrane conductance regulator with an adeno-associated virus vector. Proc. Natl. Acad. Sci. U. S. A. 90:10613-10617.

11. Wagner, J.A., et al. 2002. A phase II, double-blind, randomized, placebo-controlled clinical trial of tgAAVCF using maxillary sinus delivery in patients with cystic fibrosis with antrostomies. Hum. Gene Ther. 13:1349-1359.

12. Fisher, K.J., et al. 1997. Recombinant adeno-associated virus for muscle directed gene therapy. Nat. Med. 3:306-312.

13. Herzog, R.W., et al. 1997. Stable gene transfer and expression of human blood coagulation factor IX after intramuscular injection of recombinant adeno-associated virus. Proc. Natl. Acad. Sci. U. S. A. 94:5804-5809.

14. Wang, L., Takabe, K., Bidlingmaier, S.M., Ill, C.R., and Verma, I.M. 1999. Sustained correction of bleeding disorder in hemophilia B mice by gene therapy. Proc. Natl. Acad. Sci. U. S. A. 96:3906-3910.

15. Manning, W.C., et al. 1997. Genetic immunization with adeno-associated virus vectors expressing herpes simplex virus type 2 glycoproteins B and D. J. Virol. 71:7960-7962.

16. Liu, D.W., et al. 2000. Recombinant adeno-associated virus expressing human papillomavirus type 16 E7 peptide DNA fused with heat shock protein DNA as a potential vaccine for cervical cancer. J. Virol. 74:2888-2894.

17. Xin, K.Q., et al. 2001. A novel recombinant adenoassociated virus vaccine induces a long-term humoral immune response to human immunodeficiency virus. Hum. Gene Ther. 12:1047-1061.

18. Vandenberghe, L.H., and Wilson, J.M. 2007. AAV as an immunogen. Curr. Gene Ther. 7:325-333.

19. Sarukhan, A., et al. 2001. Successful interference with cellular immune responses to immunogenic proteins encoded by recombinant viral vectors. J. Virol. 75:269-277.

20. Vandenberghe, L.H., et al. 2006. Heparin binding directs activation of $\mathrm{T}$ cells against adeno-associated virus serotype 2 capsid. Nat. Med. 12:967-971.

21. Wang, Z., et al. 2007. Immunity to adeno-associated virus-mediated gene transfer in a random-bred canine model of Duchenne muscular dystrophy. Hum. Gene Ther. 18:18-26.

22. Wang, L., Figueredo, J., Calcedo, R., Lin, J., and Wilson, J.M. 2007. Cross-presentation of adeno-associated virus serotype 2 capsids activates cytotoxic $\mathrm{T}$ cells but does not render hepatocytes effective cytolytic targets. Hum. Gene Ther. 18:185-194.

23. Li, C., et al. 2007. Adeno-associated virus type 2 (AAV2) capsid-specific cytotoxic T lymphocytes eliminate only vector-transduced cells coexpressing the AAV2 capsid in vivo. J. Virol. 81:7540-7547.

24. Chirmule, N., et al. 2000. Humoral immunity to adeno-associated virus type 2 vectors following administration to murine and nonhuman primate muscle. J. Virol. 74:2420-2425.

25. Peden, C.S., Burger, C., Muzyczka, N., and Mandel, R.J. 2004. Circulating anti-wild-type adenoassociated virus type 2 (AAV2) antibodies inhibit recombinant AAV2 (rAAV2)-mediated, but not rAAV5-mediated, gene transfer in the brain. J. Virol. 78:6344-6359.

26. Scallan, C.D., et al. 2006. Human immunoglobulin inhibits liver transduction by AAV vectors at low AAV2 neutralizing titers in SCID mice. Blood. 107:1810-1817.

27. Iwasaki, A., and Medzhitov, R. 2004. Toll-like receptor control of the adaptive immune responses. Nat. Immunol. 5:987-995.

28. Pulendran, B., and Ahmed, R. 2006. Translating innate immunity into immunological memory: implications for vaccine development. Cell. 124:849-863.

29. Akira, S., Uematsu, S., and Takeuchi, O. 2006. Pathogen recognition and innate immunity. Cell. 124:783-801.

30. Kawai, T., and Akira, S. 2006. Innate immune recognition of viral infection. Nat. Immunol. 7:131-137.

31. Zhu, J., Huang, X., and Yang, Y. 2007. Innate immune response to adenoviral vectors is mediated by both Toll-like receptor-dependent and -independent pathways. J. Virol. 81:3170-3180.

32. Auricchio, A., Hildinger, M., O'Connor, E., Gao, G.P., and Wilson, J.M. 2001. Isolation of highly infectious and pure adeno-associated virus type 2 vectors with a single-step gravity-flow column. Hum. Gene Ther. 12:71-76.

33. Yamada, H., et al. 2002. Effect of suppressive DNA on CPG-induced immune activation. J. Immunol. 169:5590-5594.

34. Peng, G., et al. 2005. Toll-like receptor 8-mediated reversal of $\mathrm{CD} 4+$ regulatory $\mathrm{T}$ cell function. Science. 309:1380-1384.

35. Colonna, M., Trinchieri, G., and Liu, Y.J. 2004. Plasmacytoid dendritic cells in immunity. Nat. Immunol. 5:1219-1226

36. Hoshino, K., et al. 2006. IkappaB kinase-alpha is critical for interferon-alpha production induced by
Toll-like receptors 7 and 9. Nature. 440:949-953.

37. Uematsu, S., and Akira, S. 2007. Toll-like receptors and type I interferons. J. Biol. Chem. 282:15319-15323.

38. Izaguirre, A., et al. 2003. Comparative analysis of IRF and IFN-alpha expression in human plasmacytoid and monocyte-derived dendritic cells. J. Leukoc. Biol. 74:1125-1138.

39. Shinohara, M.L., et al. 2006. Osteopontin expression is essential for interferon-alpha production by plasmacytoid dendritic cells. Nat. Immunol. 7:498-506.

40. Honda, K., et al. 2005. Spatiotemporal regulation of MyD88-IRF-7 signalling for robust type-I interferon induction. Nature. 434:1035-1040.

41. Guiducci, C., et al. 2006. Properties regulating the nature of the plasmacytoid dendritic cell response to Toll-like receptor 9 activation. J. Exp. Med. 203:1999-2008.

42. Douar, A.M., Poulard, K., Stockholm, D., and Danos, O. 2001. Intracellular trafficking of adenoassociated virus vectors: routing to the late endosomal compartment and proteasome degradation. J. Virol. 75:1824-1833

43. Crozat, K., and Beutler, B. 2004. TLR7: A new sensor of viral infection. Proc. Natl. Acad. Sci. U. S. A. 101:6835-6836.

44. Wang, J.P., Asher, D.R., Chan, M., Kurt-Jones, E.A., and Finberg, R.W. 2007. Cutting edge: Antibodymediated TLR7-dependent recognition of viral RNA. J. Immunol. 178:3363-3367.

45. Zaiss, A.K., et al. 2008. Complement is an essential component of the immune response to adeno-associated virus vectors. J. Virol. 82:2727-2740.

46. Nociari, M., Ocheretina, O., Schoggins, J.W., and Falck-Pedersen, E. 2007. Sensing infection by adenovirus: Toll-like receptor-independent viral DNA recognition signals activation of the interferon regulatory factor 3 master regulator. J. Virol. 81:4145-4157.

47. Stetson, D.B., and Medzhitov, R. 2006. Recognition of cytosolic DNA activates an IRF3-dependent innate immune response. Immunity. 24:93-103.

48. Ishii, K.J., et al. 2006. A Toll-like receptor-independent antiviral response induced by double-stranded B-form DNA. Nat. Immunol. 7:40-48.

49. Zaiss, A.K., and Muruve, D.A. 2005. Immune responses to adeno-associated virus vectors. Curr. Gene Ther. 5:323-331.

50. McCaffrey, A.P., et al. 2008. The host response to adenovirus, helper-dependent adenovirus, and adeno-associated virus in mouse liver. Mol. Ther. 16:931-941.

51. Brown, B.D., et al. 2007. In vivo administration of lentiviral vectors triggers a type I interferon response that restricts hepatocyte gene transfer and promotes vector clearance. Blood. 109:2797-2805.

52. Honda, K., et al. 2003. Selective contribution of IFN-alpha/beta signaling to the maturation of dendritic cells induced by double-stranded RNA or viral infection. Proc. Natl. Acad. Sci. U. S. A. 100:10872-10877.

53. Hoebe, K., et al. 2003. Upregulation of costimulatory molecules induced by lipopolysaccharide and double-stranded RNA occurs by Trif-dependent and Trifindependent pathways. Nat. Immunol. 4:1223-1229.

54. Le Bon, A., et al. 2003. Cross-priming of CD8+ T cells stimulated by virus-induced type I interferon. Nat. Immunol. 4:1009-1015.

55. Quigley, M., Huang, X., and Yang, Y. 2008. STAT1 
signaling in CD8 $\mathrm{T}$ cells is required for their clonal expansion and memory formation following viral infection in vivo. J. Immunol. 180:2158-2164.

56. Zhu, J., Huang, X., and Yang, Y. 2007. Type I IFN signaling on both $\mathrm{B}$ and CD4 $\mathrm{T}$ cells is required for protective antibody response to adenovirus. J. Immunol. 178:3505-3510.

57. Ge, Y., Powell, S., Van Roey, M., and McArthur, J.G. 2001. Factors influencing the development of an anti-factor IX (FIX) immune response following administration of adeno-associated virus-FIX. Blood. 97:3733-3737.

58. Xiao, W., et al. 2000. Route of administration determines induction of T-cell-independent humoral responses to adeno-associated virus vectors. $\mathrm{Mol}$. Ther. 1:323-329.

59. Erhardt, A., Biburger, M., Papadopoulos, T., and Tiegs, G. 2007. IL-10, regulatory T cells, and Kupffer cells mediate tolerance in concanavalin A-induced liver injury in mice. Hepatology. 45:475-485

60. You, Q., Cheng, L., Kedl, R.M., and Ju, C. 2008. Mechanism of $\mathrm{T}$ cell tolerance induction by murine hepatic Kupffer cells. Hepatology. 48:978-990.

61. Muller, U., et al. 1994. Functional role of type I and type II interferons in antiviral defense. Science. 264:1918-1921.

62. Matsushita, T., et al. 1998. Adeno-associated virus vectors can be efficiently produced without helper virus. Gene Ther. 5:938-945.

63. Xiao, X., Li, J., and Samulski, R.J. 1998. Production of high-titer recombinant adeno-associated virus vectors in the absence of helper adenovirus. J. Virol. 72:2224-2232.

64. Auricchio, A., et al. 2002. Noninvasive gene transfer to the lung for systemic delivery of therapeutic proteins. J. Clin. Invest. 110:499-504.

65. Yang, Y., Huang, C.T., Huang, X., and Pardoll, D.M. 2004. Persistent Toll-like receptor signals are required for reversal of regulatory $\mathrm{T}$ cell-mediated CD8 tolerance. Nat. Immunol. 5:508-515.

66. Lund, J.M., et al. 2004. Recognition of singlestranded RNA viruses by Toll-like receptor 7. Proc. Natl. Acad. Sci. U. S. A. 101:5598-5603.

67. Sabatino, D.E., et al. 2005. Identification of mouse AAV capsid-specific CD8+ T cell epitopes. Mol. Ther. 12:1023-1033.

68. Huang, X., and Yang, Y. 2004. Transient gain of effector function by $\mathrm{CD} 8+\mathrm{T}$ cells undergoing peripheral tolerance to high-dose self-antigen. Eur. J. Immunol. 34:1351-1360.

69. Dzionek, A., et al. 2000. BDCA-2, BDCA-3, and BDCA-4: three markers for distinct subsets of dendritic cells in human peripheral blood. J. Immunol. 165:6037-6046.

70. Siegal, F.P., et al. 1999. The nature of the principal type 1 interferon-producing cells in human blood. Science. 284:1835-1837. 